\title{
Phytopathology
}

\section{How Knowledge of Pathogen Population Biology Informs Management of Septoria Tritici Blotch}

\author{
Bruce A. McDonald and Christopher C. Mundt
}

First author: Plant Pathology, Institute of Integrative Biology, ETH Zurich, CH-8092 Zurich, Switzerland; and second author: Department of Botany and Plant Pathology, Oregon State University, Corvallis 97331.

Accepted for publication 18 April 2016.

\begin{abstract}
McDonald, B. A., and Mundt, C. C. 2016. How knowledge of pathogen population biology informs management of Septoria tritici blotch. Phytopathology 106:948-955.

Zymoseptoria tritici (previously Mycosphaerella graminicola) causes Septoria tritici blotch (STB) on wheat. The population biology of Z. tritici has been exceptionally well characterized as a result of intensive studies conducted over nearly 30 years. These studies provided important insights into the biology, epidemiology and evolutionary history of $Z$. tritici that will prove useful for management of STB. The well-documented, rapid adaptation of $Z$. tritici populations to fungicide applications and deployment of wheat cultivars carrying both major gene and quantitative resistance reflects the high evolutionary potential predicted by the large effective population size, high degree of gene flow and high levels of recombination found in field populations of $Z$. tritici globally. $\mathrm{Q}_{\mathrm{ST}}$ studies that assessed the global diversity for several important quantitative traits confirmed the adaptive potential of field populations and laid the groundwork for quantitative trait loci (QTL) mapping studies. QTL mapping elucidated the genetic architecture of each trait and led to identification of candidate genes affecting fungicide resistance, thermal adaptation, virulence, and host specialization. The insights that emerged through these analyses of Z. tritici population biology can now be used to generate actionable disease management strategies aimed at sustainably reducing losses due to STB. The high evolutionary potential found in field populations of $Z$. tritici requires deployment of a corresponding dynamically diverse set of control measures that integrate cultural, chemical, biological and resistance breeding strategies. In this review, we describe and prioritize STB control strategies based on current knowledge of Z. tritici population biology and propose a future research agenda oriented toward long-term STB management.
\end{abstract}

\section{AN OVERVIEW OF POPULATION BIOLOGY STUDIES IN ZYMOSEPTORIA TRITICI}

Zymoseptoria tritici (Desm.) Quaedvlieg \& Crous (formerly Mycosphaerella graminicola (Fuckel) J. Schröt. in Cohn) is a globally distributed fungal pathogen causing Septoria tritici blotch (STB) on wheat. STB currently is the most damaging wheat disease in Europe (Jorgensen et al. 2014; O'Driscoll et al. 2014) and poses a significant threat in many wheat production areas around the world. STB is most damaging in humid climates, such as found in northern France, Germany, and the United Kingdom. Around $70 \%$ of annual cereal fungicide usage in the European Union (worth $\$ 1.2$ billion) is targeted toward STB (Torriani et al. 2015). Yield losses of up to $50 \%$ were documented in untreated fields planted to susceptible cultivars (Eyal et al. 1987). In the United Kingdom, annual losses average

Corresponding author: B. A. McDonald;

E-mail address: bruce.mcdonald@usys.ethz.ch

http://dx.doi.org/10.1094/PHYTO-03-16-0131-RVW

(C) 2016 The American Phytopathological Society around $20 \%$ in untreated fields, while losses of 5 to $10 \%$ are more typical in fields planted to resistant cultivars or treated with fungicides (Fones and Gurr 2015).

The origins of $Z$. tritici inform the search for resistant germplasm. Hierarchical collections made over a 25-year period enabled analysis of $\sim 3,000 \mathrm{Z}$. tritici isolates sampled from $\sim 30$ naturally infected wheat fields on five continents (Abrinbana et al. 2010; Banke and McDonald 2005; Gurung et al. 2011; Jürgens et al. 2006; Linde et al. 2002; Zhan et al. 2003). Population genetic structures of these field populations were analyzed using a series of neutral genetic markers, including restriction fragment length polymorphisms, amplified fragment length polymorphisms, and simple sequence repeats, in both nuclear and mitochondrial genomes, complemented with analyses of sequence diversity in several housekeeping genes. These studies led to discovery of a hotspot of genetic diversity in the Middle East (Banke et al. 2004; Zhan et al. 2003) and provided evidence for a founder effect resulting in lower genetic diversity in Australian populations (Zhan et al. 2003). New collections made in Iran from wheat fields and three genera of wild grasses growing in sympatry confirmed that the Middle East is a hotspot of $Z$. tritici diversity and led to the discovery of closely related Zymoseptoria 
species found exclusively on wild grasses that were unable to infect wheat (Jürgens et al. 2006; Stukenbrock et al. 2007, 2011). Coalescence dating of DNA sequences shared among Z tritici and its wild relatives showed that their last common ancestor occurred $\sim 10,000$ years ago (Stukenbrock et al. 2007). Analyses of entire genome sequences of several strains of the domesticated and wild pathogen species led to identification of 27 candidate genes likely to play a role in specialization to infect wheat (Stukenbrock et al. 2011). Three of these genes were recently functionally validated (Poppe et al. 2015) using allele swaps that showed significant changes in virulence on wheat. Taken together, these findings indicate that $Z$. tritici emerged as a host-specialized wheat pathogen $\sim 10,000$ years ago through host tracking (Stukenbrock and McDonald 2008) during the domestication of wheat (Torriani et al. 2011). This result justifies the strategy of searching for STB resistance in wild wheat relatives and wheat landraces sampled from the Fertile Crescent because these sources of germplasm are expected to have the greatest diversity for resistance as a result of their long coevolutionary history with $Z$. tritici and its closest wild relatives.

The population genetic structure of $Z$. tritici is highly diverse. Remarkably little geographical structure was found on the global scale, with an average of $92 \%$ of global pathogen diversity found within a wheat field and $84 \%$ of global diversity found within a one square meter area of any wheat field (Linde et al. 2002; Zhan et al. 2003). By comparison, only $3 \%$ of global genetic diversity was distributed among continents (Linde et al. 2002; Zhan et al. 2003). All naturally infected field populations had high genotypic diversity and low clonality (Linde et al. 2002; McDonald et al. 1996; Zhan et al. 2003), alleles at gametic equilibrium (Chen and McDonald 1996) and mating types at equal frequencies (Zhan et al. 2002a), combining to provide "the signature of sex" and indicating that Z. tritici populations are highly recombined as a result of regular cycles of sexual recombination. Asexual clones can become locally abundant over an area of a few square meters as a result of strong selection favoring splash-dispersed clones with combinations of alleles encoding higher fitness (e.g., clones carrying alleles encoding resistance to fungicides or virulence on wheat cultivars carrying major resistance (R) genes). The favored alleles in these selected clones can increase in frequency and spread to neighboring plants via splash dispersal and then be transmitted over longer distances through movement of airborne ascospores that emerge following sexual reproduction involving the selected clones (Zhan et al. 1998, 2002b). A comparison of neutral allele frequencies over time showed that Z. tritici populations were very stable (Chen et al. 1994) and enabled a calculation of an effective population size of at least 70 genotypes per square meter in naturally infected fields (Zhan et al. 2001). Careful analyses of the distribution of genotypes within lesions at the scale of $\sim 1 \mathrm{~cm}^{2}$ showed that a typical lesion contains several pathogen strains (Linde et al. 2002). These strains are likely to compete strongly for resources within infected plant tissue, with anywhere from two to six pathogen genotypes coexisting within a typical lesion. The intense competition occurring among strains in these mixed infections is likely to favor the emergence of host cultivar specialization and higher pathogen virulence. Taken together, these findings indicate that typical field populations of $Z$. tritici are characterized by a mixed reproductive system, high effective population sizes, and regular intra-host competition among strains, features that combine to facilitate rapid evolution leading to local adaptation at the field scale. This suggests that STB management strategies will need to embrace methods that increase dynamic diversity (McDonald 2014) at the field scale, as discussed later in this review.

High gene flow in $Z$. tritici indicates a need for regional management. A high degree of gene flow occurs across large spatial scales (Boeger et al. 1993) due to air dispersal of the sexually recombined ascospores that emerge from infected plants during the growing season and from infected straw and other crop debris between growing seasons. A field experiment conducted in Oregon showed that $\sim 24 \%$ of lesions found on flag leaves originated from ascospores that were generated within the same field during the growing season (Zhan et al. 1998, 2000), illustrating that airborne ascospores can provide a significant source of secondary inoculum that can be transmitted both among plants within a field and into neighboring fields. Despite the abundance of evidence for airborne ascospores moving over regional distances of tens to hundreds of kilometers, we consider it unlikely that these ascospores would often survive transit across oceans. Instead, the most likely mechanism for moving the pathogen overseas is on infected seed (Brokenshire 1975) or through international trade in straw (as shown on Alibaba, http:// www.alibaba.com/showroom/wheat-straw.html). The high regional gene flow exhibited in this pathosystem means that even best agronomic practices, such as good crop rotations coupled with careful field sanitation practices and clean seed, will not be sufficient to prevent the influx of ascospores that can lead to onset of epidemics in well-managed wheat fields. But regional-based management strategies that suppress ascospore production and release could be implemented to limit gene flow among wheat fields as discussed later.

Spatial patterns of neutral genetic markers used to measure gene flow are a result of both historical and contemporary gene flow. Genes under selection are expected to be influenced more strongly by contemporary gene flow. As a result of the high regional gene flow exhibited by $Z$. tritici, traits such as virulence or fungicide resistance that are selected in one location can be readily transported to neighboring locations. In the Willamette Valley of Oregon, for example, virulence toward major gene resistance (Cowger et al. 2000), quantitative virulence toward minor gene (quantitative) resistance (Mundt et al. 2002), single-gene resistance to strobilurin fungicides (Estep et al. 2016; Hayes et al. 2013), and tolerance toward triazole fungicides (Estep et al. 2015, 2016) quickly spread across the valley. These examples illustrate why most control methods will need to be implemented on a regional basis to achieve success.

Virulence patterns of $Z$. tritici populations differed markedly between the Willamette Valley of Oregon and the Sacramento Valley of California (Ahmed et al. 1995) despite the high similarity for neutral alleles found between these regions (Boeger et al. 1993), illustrating that gene flow is not sufficient to overcome selection for local adaptation. Hence, local management practices are expected to influence frequencies of alleles affecting virulence and fungicide insensitivity. For example, strobilurin resistance and propiconazole tolerance is now present throughout the Willamette Valley (Estep et al. 2015). However, we found larger than expected local differences in resistance associated with local management practices (Hagerty and Mundt 2015). This finding illustrates the importance of knowing the temporal scale of gene flow. For example, it may require two to three growing seasons for a trait to move 200 to $300 \mathrm{~km}$ under a stepping stone model of gene flow. In this case, growers may have 2 to 3 years of warning based on traits emerging in pathogen populations hundreds of kilometers distant before a trait like fungicide resistance selected in a distant region invades their local region. These temporal dynamics are important, as growers are more likely to adopt a control measure if there is a significant individual benefit locally, as well as a collective benefit region-wide. The effects of local versus regional control practices thus remain an important area of future research.

Quantitative traits are highly variable in field populations of $\boldsymbol{Z}$. tritici. $\mathrm{F}_{\mathrm{ST}} / \mathrm{Q}_{\mathrm{ST}}$ comparisons measure the population-scale association between quantitative traits $\left(\mathrm{Q}_{\mathrm{ST}}\right)$ and neutral genetic markers $\left(\mathrm{F}_{\mathrm{ST}}\right)$ to determine whether natural selection or genetic drift are the proximate causes of population differentiation observed for quantitative traits (Leinonen et al. 2013). $\mathrm{F}_{\mathrm{ST}} / \mathrm{Q}_{\mathrm{ST}}$ studies in $Z$. tritici showed that several quantitative traits, including virulence, fungicide sensitivity, and temperature sensitivity, were highly heritable and displayed significant variance both within field populations and globally (Zhan et al. 2005). The common garden experimental design used for the $\mathrm{Q}_{\mathrm{ST}}$ studies made it possible to 
show that many of these quantitative traits were under selection for local adaptation, reflecting local selection imposed by patterns of fungicide use, deployment of resistant cultivars and differing thermal regimes. Quantitative trait loci (QTL) mapping studies elucidated the genetic architecture of each quantitative trait and led to identification of candidate genes that may contribute to the observed variance for each trait (Lendenmann et al. 2014, 2015, 2016). These experiments also showed that the high diversity observed in field populations using neutral genetic markers is reflected by a high diversity for important quantitative traits that are likely to evolve as a result of disease management practices. Our interpretation is that enough heritable diversity for quantitative traits exists within any field population to enable a rapid adaptation of the corresponding $Z$. tritici population to most management practices, illustrating the need to apply a diversity of management practices (i.e., integrated pest management [IPM]) to force the pathogen to make trade-offs among traits. An additional benefit of the $\mathrm{Q}_{\mathrm{ST}}$ and QTL mapping experiments was the development of high throughput phenotyping methods based on automated image analysis to measure quantitative virulence (Stewart and McDonald 2014) and identify QTLs involved in virulence and cultivar specialization (Stewart et al. 2016). These methods can now be applied to measure quantitative resistance under field conditions (Stewart et al. 2016) and may prove useful in breeding programs that aim to develop quantitative resistance to STB.

A consistent outcome of all analyses was that field populations of $Z$. tritici have a high evolutionary potential at the field scale (McDonald and Linde 2002). This high evolutionary potential is consistent with field observations where $Z$. tritici populations were found to rapidly defeat major gene resistance, erode quantitative resistance, and become resistant to fungicides as described below. A replicated field experiment based on a mark-release-recapture experimental design showed how quickly selection leads to the emergence of cultivar specialization, with significant specialization emerging following only six asexual reproduction cycles in a single growing season (Zhan et al. 2002b). A recent field experiment conducted in France over a 6-year period also showed emergence of cultivar specialization (Morais et al. 2016) in which increased adaptation to one cultivar was accompanied by decreased adaptation to a second cultivar growing nearby, i.e., a trade-off was associated with host specialization. This rapid adaptation to become host specialized is likely facilitated by the high degree of among-strain competition occurring within individual plants as reflected by the within-lesion distributions of strains (Linde et al. 2002).

Populations of $\boldsymbol{Z}$. tritici evolve rapidly. Favorable environmental conditions characterized by frequent rain, cool temperatures, and high humidity result in especially rapid evolutionary responses of Z. tritici in the Willamette Valley of western Oregon, United States, providing a field laboratory for studying pathogen evolution in response to control practices (Mundt et al. 1999). There were a series of wheat cultivar turnovers in Willamette Valley in recent decades, owing primarily to selection for corresponding virulence in the regional $Z$. tritici population. Loss of major gene resistance in the cultivar 'Gene' (Cowger et al. 2000) and the substantial erosion of quantitative resistance in the cultivar 'Madsen' (Mundt et al. 2002) have already been documented. Subsequently, the cultivar 'Foote', released in 1998, attained the majority of the Willamette Valley wheat acreage by the early/mid-2000s, owing to a combination of favorable yield and resistance to STB, before succumbing to serious stripe rust outbreaks in 2004 and 2005. Z. tritici isolates collected from Foote at the ends of the 2004 and 2005 growing seasons were found to be highly virulent on Foote in greenhouse assays, but isolates collected from Madsen usually were not highly virulent on Foote (Krenz et al. 2008). Our interpretation of this virulence pattern is that the quantitative resistance of Foote to STB was in the process of eroding when it was withdrawn from production due to stripe rust susceptibility. 'Goetze' was listed as moderately resistant to STB at release in 2007 (Flowers and
Peterson 2008) and quickly became the most popular cultivar in Willamette Valley. The presence of stripe rust complicated evaluation of STB resistance in Goetze for several years, though there were strong indications of erosion of STB resistance. A clear evaluation of STB resistance in 2015 in the absence of stripe rust showed that Goetze had STB severity identical to that of the susceptible check 'Stephens' (C. C. Mundt, unpublished data), indicating that the quantitative resistance in Goetze was no longer effective. The latest quantitatively resistant cultivar, 'Bobtail', was released in 2013 and dominated the Willamette Valley wheat area in 2015, yet some evidence of erosion of its STB resistance has already appeared (C. C. Mundt, unpublished data). It thus appears that the Z. tritici population in Willamette Valley had the capacity to adapt rapidly to every major wheat cultivar that has been grown in the last 20 years, irrespective of whether the resistance was qualitative or quantitative. An important goal for future studies should be to determine whether such rapid adaptation to host resistance occurs in other geographic regions in which STB is a limiting factor to wheat production.

Z. tritici also rapidly evolved resistance or tolerance to major fungicide classes in Willamette Valley. Fungicide applications on wheat in the Willamette Valley increased substantially in recent years owing to a variety of biological and economic factors (Estep et al. 2015). Collections of $Z$. tritici isolates from experimental plots in 2012 indicated that $46 \%$ of isolates were resistant to strobilurin fungicides (Estep et al. 2013), and molecular analyses suggested several independent origins of the G143A mutation for strobilurin resistance, as well as multiple mutations for tolerance to triazole fungicides in the CYP51 gene (Estep et al. 2015). In experimental field plots, there was a rapid increase in the frequency of strobilurin resistance in response to azoxystrobin application, and also a strong suggestion of increased tolerance to propiconazole (Estep et al. 2016). In commercial wheat fields, azoxystrobin resistance increased to $93 \%$ of isolates by 2015 , with resistance increasing even over the winter, when fungicides are not applied (Hagerty and Mundt 2015). Thus, the Willamette Valley experience has been similar to that of Europe (Brunner et al. 2008; Cools and Fraaije 2013; Fraaije et al. 2012; Torriani et al. 2009), where intensive fungicide applications on wheat began much earlier and gene flow was also implicated in movement of alleles encoding fungicide resistance. In both Europe (Cools and Fraaije 2013; Fraaije et al. 2012) and Willamette Valley (C. C. Mundt, unpublished data) there has been more recent emphasis on using mixtures of triazole fungicides, as well as use of the newer succinate dehydrogenase inhibitor class of fungicides. In Europe, older multisite fungicides such as chlorothalonil also are being used to manage fungicide resistance in Z. tritici. Interestingly, in Willamette Valley, multiple field applications of chlorothalonil during the growing season increased the aggressiveness of the treated $Z$. tritici population when subsequently tested in the greenhouse (Cowger and Mundt 2002). A significant correlation between virulence and azole sensitivity was also found in the $\mathrm{Q}_{\mathrm{ST}}$ studies (Yang et al. 2013).

Given the proven ability of $Z$. tritici populations to adapt rapidly to a range of host cultivars and fungicide classes, alternative approaches to disease management are clearly needed. Such approaches should include more intensive use of cultural practices to reduce the pathogen's effective population size, as well as the use of dynamic diversity (McDonald 2014) to lessen directional selection for virulence and fungicide resistance. These approaches are discussed in the next section.

\section{STB MANAGEMENT STRATEGIES THAT TAKE INTO ACCOUNT Z. TRITICI POPULATION BIOLOGY}

The over-riding disease management principle is the need to counter the high level of pathogen diversity with a corresponding increase in agroecosystem diversity that fluctuates on a regular basis (e.g., every few years). This dynamic diversity can be implemented in 
many ways (McDonald 2014). For example, wheat fields can be planted to rotating mixtures of wheat cultivars carrying different resistance genes and be treated by rotating mixtures of fungicides having different modes of action. The reason for increasing diversity at the field scale and routinely changing the nature of that diversity is to present the pathogen population with an evolutionary dilemma that leads to disruptive selection and forces pathogen trade-offs. For example, the effector gene mutation that enables a $Z$. tritici strain to overcome a major R-gene may decrease fitness on a wheat cultivar lacking that R-gene (e.g., as found for the barley scald pathogen by Abang et al. 2006) or impose a trade-off that lowers overall pathogen reproduction, transmission, or virulence (Alizon et al. 2009; Morais et al. 2016; Sacristan and Garcia-Arenal 2008; Thrall and Burdon 2003). Similarly, a CYP51 mutation that decreases sensitivity to one azole fungicide may increase sensitivity to a different azole fungicide (Leroux et al. 2007). Integrated pathogen management strategies will likely be the key to long-term success in control of STB.

The importance of stubble management. A major contributor to the emergence of $Z$. tritici as an important wheat pathogen is that farmers adopted low-till or no-till practices to preserve soil. All farmers face a challenging trade-off between preserving soil and increasing disease because reduced tillage practices that preserve soil by leaving plant stubble on the soil surface also favor the survival of stubble-borne pathogens and increase their numbers. The increase in wheat stubble provides a larger nutrient base on which $Z$. tritici populations can survive between growing seasons and increase during the saprotrophic stage of their life cycle. This drives an increase in the pathogen effective population size and enables a corresponding increase in the number of mutations available for selection to act upon, increasing the evolutionary potential of these pathogen populations. Traditional sanitation practices, such as crop rotations, burning or burying crop residue, and planting disease-free seed, can reduce the level of primary inoculum in individual fields, but the large number of $Z$. tritici airborne ascospores immigrating from neighboring fields will be sufficient to initiate an epidemic, even in fields with excellent sanitation practices (Schuh 1990). Thus, practices such crop rotation and tillage have little influence on final levels of STB on a local scale (Bailey et al. 2001; Leath et al. 1993; Schuh 1990; Suffert and Sache 2011). Effective stubble management will therefore likely require region-wide implementation that, though desirable, may be very difficult to achieve.

Fortunately, several approaches can be used to reduce Z. tritici effective population size through better stubble management. Any strategies that reduce the production of ascospores or limit their spread will also serve to reduce the amount of gene flow among fields by limiting the number of wind-blown spores moving within a region. An important factor may be the vertical position of pseudothecia within the stubble. Pfender and Wootke (1988) found that pseudothecia of Pyrenophora tritici-repentis survived well in standing straw and upper mulch layers but not in straw or mulch located in the soil or directly on the soil surface. It is likely that there are similar positional effects with $Z$. tritici, suggesting that standing straw should be cut down at ground level to enable closer contact of loose straw with the soil surface. An obvious stubble management strategy is to remove straw from the field after harvesting the grain. The straw could be cut off at ground level, baled and used for bioenergy (by burning or converting to cellulosic biofuels), animal feed, or composted ex situ after covering the straw with a tarp to prevent escape of ascospores. Any strategy that removes straw from the field is likely to lower organic matter in the soil and may diminish soil fertility, hence in situ stubble management may be preferred.

An in situ stubble management strategy is to plant fall-sown cover crops such as crimson clover or vetch that grow quickly to cover the wheat stubble left in the field. In this case, the cover crop serves as a trap that captures most of the ascospores being generated on the straw and prevents them from blowing away to infect neighboring fields. A complementary in situ strategy is to apply microbial biological control agents that can decay the stubble more quickly as well as out-compete $Z$. tritici on the stubble or even act as predators of $Z$. tritici, causing a significant reduction in the number of ascospores that will emerge from the stubble. Based on experimental findings in other cereal stubble pathogens (Parastagonospora nodorum, Sommerhalder et al. 2011 and Rhychosporium commune, Abang et al. 2006) it is likely that selection processes operating during the saprotrophic stage of the life cycle on stubble differ significantly from selection processes operating during the biotrophic and necrotrophic stages of the life cycle on living plants, consistent with trade-offs between parasitic competitive ability and saprophytic competitive ability. Intensive stubble management may increase these trade-offs and favor the emergence of less virulent or less specialized strains and populations.

Resistance breeding and deployment strategies. Another important foundation for STB management is to breed for higher STB resistance in new wheat cultivars. Several resistance breeding strategies can be used to implement the concept of dynamic diversity (McDonald 2014). A logical starting point is to combine major and minor R-genes that have already been identified in existing wheat cultivars (Brown et al. 2015) because these resistance genes are already in adapted backgrounds. But new sources of quantitative and major gene resistance should also be sought in wheat landraces and wild wheat relatives growing in the Fertile Crescent where Z. tritici originated. Given that the vast majority of pathogen virulence is quantitative (Stewart and McDonald 2014; Zhan et al. 2007), we believe that the goal of breeding programs should be to accumulate several independent quantitative resistance genes. New automated digital image analysis methods that directly measure $Z$. tritici reproduction on adult plants under field conditions (Stewart and McDonald 2014; Stewart et al. 2016) provide a powerful tool to differentiate degrees of quantitative resistance exhibited by breeding lines. Breeding nurseries focused on STB should be located in regions, such as Willamette Valley, that exhibit consistent, high levels of natural STB infection. This would complement local testing and provide a broader measure of the likely durability of chosen sources of resistance over larger geographical scales. If natural infection is not reliably consistent in local breeding nurseries, a genetically diverse mixture of local strains (we suggest using at least 8 to 10 local strains) should be applied to the breeding material to mimic better the natural infections that occur in local field environments. A recent study illustrated how fungicide treatments could be used to separate the effects of STB from other competing diseases in field experiments (Stewart et al. 2016), providing a new method to increase the efficiency of selection for STB resistance under field conditions.

Optimal R-gene deployment strategies for durable resistance to STB are likely to differ compared with other pathosystems, such as the mainly asexual and clonal cereal rusts and Phytophthora pathogens. The high evolutionary potential of $Z$. tritici is likely to make use of single major resistance genes even less durable compared with less diverse systems and, thus, not a viable option. For example, the Oregon cultivar Gene carries the Stb6 major R-gene that is found in wheat cultivars around the world (Chartrain et al. 2005), but the resistance in Gene lasted only three years before the local $Z$. tritici population evolved to overcome it (Cowger et al. 2000). Pyramiding major R-genes may increase durability of resistance for mainly asexual pathogens, but the durability of such pyramids will depend on the probabilities of accumulating corresponding virulence mutations in the pathogen (Schafer and Roelfs 1985) and these probabilities will be higher in sexually recombining pathogen populations. Hence, major R-gene pyramids may exhibit low durability for Z. tritici owing to the large effective population sizes and the high degree of sexual recombination in populations of this pathogen (Chen and McDonald 1996; McDonald and Linde 2002). More promising approaches would be to identify specific combinations of resistance genes that lead to reduced fitness in pathogen strains carrying corresponding 
virulence mutations (Green and Campbell 1979; Mundt 1990; Vanderplank 1975; Wolfe 1973; Wolfe and Barrett 1977) or to combine major seedling R-genes with quantitative adult-plant R-genes, an approach that has proven highly successful at CIMMYT for controlling wheat stem rust (Rajaram et al. 1988). Another approach is to pyramid a large number of quantitative R-genes to increase the level of resistance via additive gene action. This can be accomplished by crossing agronomically favorable parents, each of which possess different minor genes for quantitative resistance. A combination of field assessments and marker-assisted selection may be helpful in selecting parents to be crossed and in evaluating the resulting progeny. It also is logical to expect that accumulating a larger number of quantitative R-genes will increase durability of this resistance because a larger number of genetic changes would need to accumulate in the corresponding Z tritici population to erode resistance. An additional advantage of quantitative resistance is that the selection leading to erosion of quantitative resistance (which allows some pathogen reproduction) is much less efficient than the selection leading to breakdown of major R-genes (which prevent pathogen reproduction). Any resistance breeding or R-gene deployment strategy should consider the concept of dynamic diversity (McDonald 2014), whereby new combinations of R-genes are continuously rotated through an agroecosystem to impose disruptive selection on the associated pathogen population.

The effects of host genetic diversity on $Z$. tritici populations are not well understood and represent an important area for future research. Variety mixtures for STB control have a mixed record in the experimental literature. A reasonable decline in disease severity occurs when mixtures contain cultivars exhibiting large differences in resistance and when highly resistant cultivars comprise a large proportion of the mixture (Gigot et al. 2013; Gigot et al. 2014; Mundt et al. 1995). For mixtures of cultivars exhibiting smaller differences in quantitative resistance, disease reductions have been much lower (Cowger and Mundt 2002; Jackson and Wennig 1997; Mundt et al. 1995). Deployment of a diverse array of major R-genes is expected to suppress evolution toward accumulation of specific virulence genes (Mundt 2002), though it has not yet been tested whether the diverse, highly recombining $Z$. tritici populations will accumulate corresponding virulence genes more rapidly. An interesting question will be whether mixtures of cultivars with quantitative resistance will lead to increased durability of minor gene resistance, given that quantitative resistance to STB has already been shown to erode when grown in extensive monocultures (as described earlier). When pathogens adapt quantitatively to differing host genetic backgrounds in a cultivar mixture, disruptive selection may slow pathogen evolution toward increased virulence as the pathogen is dispersed among different cultivars (Chin and Wolfe 1984; Wolfe 1985). Evidence from a replicated field experiment with STB suggested that such disruptive selection may be operating (Mundt et al. 1999; Zhan et al. 2002b). However, a subsequent study showed that mixtures of cultivars expressing quantitative resistance may decrease, increase, or have no effect on Z. tritici aggressiveness in mixtures, depending upon the year of study (Cowger and Mundt 2002). Given the strong evidence for erosion of quantitative resistance in STB (see above), an area that requires further work is to determine if initial release of novel sources of quantitative resistance in mixtures will increase durability. Spatial deployment of cultivars with different sources of resistance (both major and minor) within a region would logically be expected to contribute to resistance durability. But as with several other aspects of STB control, regional diversification will be very difficult to study experimentally, and may require a rigorous combination of empirical and modeling efforts.

Biological control should use a consortium of microbes. Biological control of STB has been explored and shows promise (Kildea et al. 2008; Perelló et al. 2009), but is not yet widely utilized to manage STB. As described earlier, we believe that more attention should be paid to biological control during the saprophytic stage of the life cycle, in particular on the straw and stubble where $Z$. tritici populations survive and increase between growing seasons. Given the proven ability of $Z$. tritici to adapt rapidly to single gene resistances and single target fungicides, we consider it likely that Z. tritici populations would also adapt rapidly to counter the effects of biocontrol agents deployed as a single strain. Hence, we suggest that biocontrol strategies should be oriented around developing a consortium of microbes composed of different species that could be applied as a mixture to either straw or living tissue.

Management of fungicides to delay the emergence of fungicide resistance. Fungicides are commonly used to control STB in Europe and are increasingly used to control STB in North America. As described earlier, the result in both locations has been emergence of resistant $Z$. tritici populations. A simple resistance management strategy is to apply fungicides as mixtures or alternations that target different biochemical pathways (Mikaberidze et al. 2014). But routine applications of mixtures may lead to more rapid emergence of multidrug resistance through Mendelian recombination that brings together mutant alleles of the individual genes encoding the different fungicide targets (e.g., mutant CYP51 alleles that encode resistance to azoles can recombine with mutant $\beta$-tubulin alleles that encode resistance to benzimidazoles) or through mutations in genes affecting the activity of fungicide efflux pumps such as $\mathrm{ABC}$ transporters and major facilitator superfamily transporters (Kretschmer et al. 2009), as recently discovered in French populations of Z tritici (Omrane et al. 2015). A complement to the mixture strategy is to lower the overall amount of fungicide applied in the agroecosystem, assuming that the degree of selection is proportional to the amount of fungicide applied to the pathogen population. For example, lower than recommended doses of fungicides can be applied to decrease selection for mutations that encode high levels of resistance (Mavroeidi and Shaw 2006). Similarly, fewer fungicide applications can be made during the growing season while increasing the focus on late-season applications that protect the flag leaf. In general, multiple applications of high doses across the growing season are expected to select for resistance more quickly than fewer applications applied at lower doses. The overall strategy for fungicide use should be to minimize directional selection that favors mutations encoding high levels of resistance while maximizing disruptive selection that will force trade-offs with other traits. To implement this strategy at the field scale, a wheat farmer should use mixtures of fungicides with different modes of action, applied at the lowest effective dose (Paveley et al. 2001), with applications timed to maximize protection of the flag leaf. The fungicide mixture should be changed at regular intervals (i.e., within a season or annually) to achieve dynamic diversity that will impose disruptive selection on the corresponding pathogen population. It will be important to avoid using the same fungicide or the same fungicide mixture over a large area and for many years.

Quarantines can still be useful in regions with limited pathogen diversity. One important outcome of the global analyses of genetic and phenotypic diversity was the finding that Australian populations of $Z$. tritici are less diverse than other populations (Zhan et al. 2003), likely as a result of a founder effect. It is possible that other, uncharacterized regions such as South Africa also benefit from lower pathogen diversity as a result of founder effects. In these cases, quarantines can be very important to restrict the introduction of novel genetic diversity that would increase the evolutionary potential of the local pathogen population as well as increasing the risk of introducing novel and undesirable alleles encoding fungicide resistance or higher levels of virulence. Hence, quarantines may still offer an effective management strategy even after STB has become widely distributed across a large country such as Australia.

Cultural control measures. Given the strong influence of fall ascospore infections on STB epidemics, delayed fall planting should allow the crop to escape many of these infections. Indeed, delayed fall planting generally reduces the severity of STB 
(Broscious et al. 1985; Gladders et al. 2001; Krupinsky 1999; Lovell et al. 1997). Delayed planting also contributes to reduced levels of several other wheat diseases (e.g., eyespot, sharp eyespot, take-all, yellow dwarf viruses, and stripe rust) in addition to STB. Delaying planting beyond a certain date can increase the risk of being unable to establish the crop owing to wet soils, and yield potential may be reduced if planting is delayed for too long. Thus, planting should be delayed only as long as is feasible under local agronomic conditions. The practical length of delay can be expanded in some cases through use of alternative planting equipment (e.g., larger drills or broadcast seeders) that allow a given area to be planted in a shorter period of time.

Nitrogen fertilization rate can affect STB through a number of effects on tissue susceptibility, as well as through canopy effects on microclimate and splash dispersal (Lovell et al. 1997; Walters and Binghamnn 2007). The effect of nitrogen level on STB is further complicated by the coexistence of biotrophic, necrotrophic, and saprotrophic stages of the pathogen life cycle (Ponomarenko et al. 2011), which may respond differently to nitrogen status. It is thus not surprising that effects of nitrogen fertilization on STB are variable (Krupinsky 1999). Nonetheless, nitrogen effects generally tend toward increasing disease with increasing $\mathrm{N}$ rate (Broscious et al. 1985; Krupinsky 1999; Lovell et al. 1997; Walters and Binghamnn 2007). From a practical standpoint, nitrogen rates should be those required to attain optimum economic yield, as nitrogen application beyond that level may unnecessarily increase STB. Similar arguments can be made for the effect of seeding rates on STB, which are variable but tend toward a positive relationship between seeding density and STB severity (Baccar et al. 2011; Broscious et al. 1985; Krupinsky 1999; Lovell et al. 1997).

\section{A RANKING OF STB MANAGEMENT STRATEGIES BASED ON Z. TRITICI POPULATION BIOLOGY}

We tried to illustrate how new knowledge that arose out of population biology research could be applied to manage STB in different parts of this review, but we did not discuss the relative ease of applying these management strategies nor their likely overall impact on disease control. Here we present a ranking of different management strategies after taking into account their ease of implementation and their likely overall impact on management of $\mathrm{STB}$, ordered from highest to lowest priority.

1. Resistance breeding should place an increased emphasis on accumulating independent sources of quantitative resistance.

2. Wheat cultivars carrying diverse sources of resistance should be deployed dynamically across smaller spatial and temporal scales to increase disruptive selection.

3. Improve the implementation and integration of different disease management strategies, for example integrate planting resistant cultivars with applying fungicide mixtures and regional stubble management.

4. Use dynamic deployment of fungicides based on mixtures and frequent changes in active ingredients to increase disruptive selection.

5. Improve stubble management across regional scales to significantly reduce the number of airborne ascospores.

6. Maintain or improve quarantine vigilance for countries harboring $Z$. tritici populations that have low genetic and phenotypic diversity.

\section{CONCLUSIONS}

While the focus of this review was on STB caused by Z. tritici, the same disease management principles should be applicable to other stubble-borne pathogens with similar population biology and life histories, including Parastagonospora nodorum, Pyrenophora tritici-repentis, Rhynchosporium commune, and Fusarium graminearum. Aggressive stubble management is likely to improve control of diseases caused by these pathogens by decreasing pathogen population size, with subsequent reductions in evolutionary potential. In general, different management practices should be integrated and dynamic diversity should be implemented in order to achieve a sustained reduction in STB. Combining multiple management practices with small individual effect can sometimes provide larger combined effects in terms of disease control (Mundt et al. 2002; Quincke et al. 2014). Combining management practices is also likely to slow pathogen evolution toward increased virulence, host specialization, and fungicide resistance by reducing pathogen population size and introducing evolutionary roadblocks such as disruptive selection and trade-offs among traits. Combining practices also reduces the risk of a catastrophic yield loss under conditions of fungicide failure and/or highly conducive environmental conditions.

\section{SOME IMPORTANT QUESTIONS TO DIRECT FUTURE RESEARCH}

We finish this review by posing a series of questions that we consider important to direct future research oriented toward limiting damage caused by STB.

Q1. How does deployment of different forms of host resistance influence the development of STB epidemics and the response of the corresponding $Z$. tritici population, given the high diversity and large effective population size of Z. tritici? Much of the work on gene deployment (e.g., pyramids, minor gene resistance, mixtures, gene rotation, regional deployment, etc.) has been oriented around pathogens that are mainly asexual and experience frequent genetic bottlenecks. Z tritici may respond very differently.

Q2. Will major gene and minor gene resistance be as ephemeral as current evidence suggests? Much of the evidence comes from one location, the Willamette Valley of Oregon, and it is unclear if this will be a general response in all wheat-growing regions.

Q3. How can fungicides best be managed to thwart directional selection for resistance? Evolution in the real world is likely to be more complex than our current theory and models allow. Well-designed empirical tests of different fungicide deployment strategies are greatly needed.

Q4. Do different management practices with modest individual effects provide significant disease control when used in combination? Such positive synergy is generally assumed, but few field data exist to provide a reasonable test of this assumption.

Q5. Can stubble be managed on a regional basis to suppress STB epidemics? Sexual reproduction on straw of previous crops is crucial to development of STB epidemics and contributes significantly to the pathogen's diversity and population size. The efficacy of stubble management practices and the extent to which such practices must be deployed to have substantial impacts are largely unknown.

Q6. To what degree do different management practices have local versus regional impacts on STB epidemics and Z. tritici evolution? If management practices have both local and regional impacts, growers will have greater incentive to adopt them.

\section{ACKNOWLEDGMENTS}

B. A. McDonald acknowledges receipt of a fellowship from the OECD Co-operative Research Programme, Biological Resource Management for Sustainable Agricultural Systems in 2015 as well as grant funding from the Swiss National Science Foundation (31003A_134755 and 31003A_155955). C. C. Mundt acknowledges funding from the Oregon Agricultural Experiment Station, the Oregon Wheat Commission, the Oregon State University Wheat 
Breeding Program, and the NSF/NIH/USDA/BBSRC Ecology and Evolution of Infectious Disease (EEID) Program through NSF award 052756, NIH award R01GM96685, and USDA-NIFA award 2015-67013-23818.

\section{LITERATURE CITED}

Abang, M., Zhan, J., Yahyaoui, A., Ceccarelli, S., Baum, M., Grando, S., Linde, C. C., and McDonald, B. A. 2006. Differential selection on Rhynchosporium secalis during parasitic and saprophytic phases in the barley scald disease cycle. Phytopathology 96:1214-1222.

Abrinbana, M., Mozafari, J., Shams-Bakhsh, M., and Mehrabi, R. 2010. Genetic structure of Mycosphaerella graminicola populations in Iran. Plant Pathol. 59:829-838.

Ahmed, H. U., Mundt, C. C., and Coakley, S. M. 1995. Host-pathogen relationship of geographically diverse isolates of Septoria tritici and wheat cultivars. Plant Pathol. 44:838-847.

Alizon, S., Hurford, A., Mideo, N., and Van Baalen, M. 2009. Virulence evolution and the trade-off hypothesis: History, current state of affairs and the future. J. Evol. Biol. 22:245-259.

Baccar, R., Fournier, C., Dornbusch, T., Andrieu, B., Gouache, D., and Robert, C. 2011. Modelling the effect of wheat canopy architecture as affected by sowing density on Septoria tritici epidemics using a coupled epidemicvirtual plant model. Ann. Bot. (Lond.) 108:1179-1194.

Bailey, K. L., Gossen, B. D., Lafond, G. P., Watson, P. R., and Derksen, D. A. 2001. Effect of tillage and crop rotation on root and foliar diseases of wheat and pea in Saskatchewan from 1991 to 1998: Univariate and multivariate analyses. Can. J. Plant Sci. 81:789-803.

Banke, S., and McDonald, B. A. 2005. Migration patterns among global populations of the pathogenic fungus Mycosphaerella graminicola. Mol. Ecol. 14:1881-1896.

Banke, S., Peschon, A., and McDonald, B. A. 2004. Phylogenetic analysis of globally distributed Mycosphaerella graminicola populations based on three DNA sequence loci. Fungal Genet. Biol. 41:226-238.

Boeger, J. M., Chen, R. S., and McDonald, B. A. 1993. Gene flow between geographic populations of Mycosphaerella graminicola (anamorph Septoria tritici) detected with RFLP markers. Phytopathology 83:1148-1154.

Brokenshire, T. 1975. Wheat seed infection by Septoria triad. Trans. Br. Mycol. Soc. 64:331-334.

Broscious, S. C., Frank, J. A., and Frederick, J. R. 1985. Influence of winter wheat management practices on the severity of powdery mildew and Septoria blotch in Pennsylvania. Phytopathology 75:538-542.

Brown, J. K., Chartrain, L., Lasserre-Zuber, P., and Saintenac, C. 2015. Genetics of resistance to Zymoseptoria tritici and applications to wheat breeding. Fungal Genet. Biol. 79:33-41.

Brunner, P. C., Stefanato, F. L., and McDonald, B. A. 2008. Evolution of the CYP51 gene in Mycosphaerella graminicola: Evidence for intragenic recombination and selective replacement. Mol. Plant Pathol. 9:305-316.

Chartrain, L., Brading, P. A., and Brown, J. K. M. 2005. Presence of the Stb6 gene for resistance to Septoria tritici blotch (Mycosphaerella graminicola) in cultivars used in wheat-breeding programmes worldwide. Plant Pathol. 54:134-143.

Chen, R. S., Boeger, J. M., and McDonald, B. A. 1994. Genetic stability in a population of a plant pathogenic fungus over time. Mol. Ecol. 3:209-218.

Chen, R. S., and McDonald, B. A. 1996. Sexual reproduction plays a major role in the genetic structure of populations of the fungus Mycosphaerella graminicola. Genetics 142:1119-1127.

Chin, K. M., and Wolfe, M. S. 1984. Selection on Erysiphe graminis in pure and mixed stands of barley. Plant Pathol. 33:535-546.

Cools, H. J., and Fraaije, B. A. 2013. Update on mechanisms of azole resistance in Mycosphaerella graminicola and implications for future control. Pest Manag. Sci. 69:150-155.

Cowger, C., Hoffer, M. E., and Mundt, C. C. 2000. Specific adaptation by Mycosphaerella graminicola to a resistant wheat cultivar. Plant Pathol. 49:445-451.

Cowger, C., and Mundt, C. C. 2002. Effects of wheat cultivar mixtures on epidemic progression of Septoria tritici blotch and pathogenicity of Mycosphaerella graminicola. Phytopathology 92:617-623.

Estep, L. K., Sackett, K. E., Anderson, N. P., Flowers, M. D., and Mundt, C. C. 2016. Evidence of within-season selection for fungicide resistance in Zymoseptoria tritici populations in western Oregon. Plant Dis. 100:483-489.

Estep, L. K., Torriani, S. F. F., Zala, M., Anderson, N. P., Flowers, M. D., McDonald, B. A., Mundt, C. C., and Brunner, P. C. 2015. Emergence and early evolution of fungicide resistance in North American populations of Zymoseptoria tritici. Plant Pathol. 64:961-971.

Estep, L. K., Zala, M., Anderson, N. P., Sackett, K. E., Flowers, M., McDonald, B. A., and Mundt, C. C. 2013. First report of resistance to QoI fungicides in North American populations of Zymoseptoria tritici, causal agent of Septoria tritici blotch of wheat. Plant Dis. 97:1511.
Eyal, Z., Scharen, A. L., Prescott, J. M., and van Ginkel, M. 1987. The Septoria Diseases of Wheat: Concepts and Methods of Disease Management. CIMMYT, Mexico.

Flowers, M., and Peterson, C. J. 2008. Goetze Soft White Winter Wheat. EM 8957-E. Oregon State University Extension Service, Corvallis, OR.

Fones, H., and Gurr, S. 2015. The impact of Septoria tritici blotch disease on wheat: An EU perspective. Fungal Genet. Biol. 79:3-7.

Fraaije, B. A., Bayon, C., Atkins, S., Cools, H. J., Lucas, J. A., and Fraaije, M. W. 2012. Risk assessment studies on succinate dehydrogenase inhibitors, the new weapons in the battle to control Septoria leaf blotch in wheat. Mol. Plant Pathol. 13:263-275.

Gigot, C., de Vallavieille-Pope, C., Huber, L., and Saint-Jean, S. 2014. Using virtual 3-D plant architecture to assess fungal pathogen splash dispersal in heterogeneous canopies: A case study with cultivar mixtures and a nonspecialized disease causal agent. Ann. Bot. 114:863-876.

Gigot, C., Saint-Jean, S., Huber, L., Maumené, C., Leconte, M., Kerhornou, B., and de Vallavieille-Pope, C. 2013. Protective effects of a wheat cultivar mixture against splash-dispersed Septoria tritici blotch epidemics. Plant Pathol. 62:1011-1019.

Gladders, P., Pavely, N. D., Barrie, I. A., Hardwick, N. V., Hims, M. J., Langton, S., and Taylor, M. C. 2001. Agronomic and meteorological factors affecting the severity of leaf blotch caused by Mycosphaerella graminicola in commercial wheat crops in England. Ann. Appl. Biol. 138:301-311.

Green, G. J., and Campbell, A. P. 1979. Wheat cultivars resistant to Puccinia graminis tritici in western Canada: Their development, performance, and economic value. Can. J. Plant Pathol. 1:3-11.

Gurung, S., Goodwin, S. B., Kabbage, M., Bockus, W. W., and Adhikari, T. B. 2011. Genetic differentiation at microsatellite loci among populations of Mycosphaerella graminicola from California, Indiana, Kansas, and North Dakota. Phytopathology 101:1251-1259.

Hagerty, C. H., and Mundt, C. C. 2015. Page 41 in: Temporal dynamics of Zymoseptoria tritici fungicide resistance in the Willamette Valley, USA. Resistance 2015. Rothamsted Research, Harpenden, UK.

Hayes, L. E., Zala, M., Anderson, N. P., Sackett, K. E., Flowers, M., McDonald, B. A., and Mundt, C. C. 2013. First report of resistance to QoI fungicides in North American populations of Zymoseptoria tritici, causal agent of Septoria tritici blotch of wheat. Plant Dis. 97:5011.

Jackson, L. F., and Wennig, R. W. 1997. Use of wheat cultivar blends to improve grain yield and quality and reduce disease and lodging. Field Crops Res. 52:261-269.

Jorgensen, L. N., Hovmoller, M. S., Hansen, J. G., Lassen, P., Clark, B., and Bayles, R. 2014. IPM strategies and their dilemmas including an introduction to www.eurowheat.org. J. Integr. Agric. 13:265-281.

Jürgens, T., Linde, C. C., and McDonald, B. A. 2006. Genetic structure of Mycosphaerella graminicola populations from Iran, Argentina and Australia. Eur. J. Plant Pathol. 115:223-233.

Kildea, S., Ransbotyn, V., Khan, M. R., Fagan, B., Leonard, G., Mullins, E., and Doohan, F. M. 2008. Bacillus megaterium shows potential for the biocontrol of Septoria tritici blotch of wheat. Biol. Control 47:37-45.

Krenz, J. E., Sackett, K. E., and Mundt, C. C. 2008. Specificity of incomplete resistance to Mycosphaerella graminicola in wheat. Phytopathology 98: 555-561.

Kretschmer, M., Leroch, M., Mosbach, A., Walker, A. S., Fillinger, S., Mernke, D., Schoonbeek, H. J., Pradier, J. M., Leroux, P., De Waard, M. A., and Hahn, M. 2009. Fungicide-driven evolution and molecular basis of multidrug resistance in field populations of the grey mould fungus Botrytis cinerea. PLoS Pathog. 5:e1000696.

Krupinsky, J. M. 1999. Influence of cultural practices on Septoria/Stagonospora diseases. Pages 108-110 in: Septoria and Stagonospora Diseases of Cereals: A Compilation of Global Research. M. van Ginkel, A. McNab, and J. Krupinsky, eds. CIMMYT, Mexico, D.F.

Leath, S., Scharen, A. L., Lund, R. E., and Dietz-Holmes, M. E. 1993. Factors associated with global occurrences of Septoria nodorum blotch and Septoria tritici blotch of wheat. Plant Dis. 77:1266-1270.

Leinonen, T., McCairns, R. J. S., O’Hara, R. B., and Merilä, J. 2013. $Q_{\mathrm{ST}}-F_{\mathrm{ST}}$ comparisons: Evolutionary and ecological insights from genomic heterogeneity. Nat. Rev. Genet. 14:179-190.

Lendenmann, M. H., Croll, D., and McDonald, B. A. 2015. QTL mapping of fungicide sensitivity reveals novel genes and pleiotropy with melanization in the pathogen Zymoseptoria tritici. Fungal Genet. Biol. 80:53-67.

Lendenmann, M. H., Croll, D., Palma-Guerrero, J., Stewart, E. L., and McDonald, B. A. 2016. QTL mapping of temperature sensitivity reveals candidate genes for thermal adaptation and growth morphology in the plant pathogenic fungus Zymoseptoria tritici. Heredity 116:384-394.

Lendenmann, M. H., Croll, D., Stewart, E. L., and McDonald, B. A. 2014. Quantitative trait locus mapping of melanization in the plant pathogenic fungus Zymoseptoria tritici. G3: Genes, Genomes, Genetics 4:2519-2533.

Leroux, P., Albertini, C., Gautier, A., Gredt, M., and Walker, A. S. 2007. Mutations in the cyp51 gene correlated with changes in sensitivity to sterol 
$14 \alpha$-demethylation inhibitors in field isolates of Mycosphaerella graminicola. Pest Manag. Sci. 63:688-699.

Linde, C., Zhan, J., and McDonald, B. A. 2002. Population structure of Mycosphaerella graminicola: From lesions to continents. Phytopathology 92:946-955.

Lovell, D. J., Parker, S. R., Hunter, T., Royle, D. J., and Coker, R. R. 1997. Influence of crop growth and structure on the risk of epidemics by Mycosphaerella graminicola (Septoria tritici) in winter wheat. Plant Pathol. 46:126-138.

Mavroeidi, V. I., and Shaw, M. W. 2006. Effects of fungicide dose and mixtures on selection for triazole resistance in Mycosphaerella graminicola under field conditions. Plant Pathol. 55:715-725.

McDonald, B. A. 2014. Using dynamic diversity to achieve durable disease resistance in agricultural ecosystems. Trop. Plant Pathol. 39:191-196.

McDonald, B. A., and Linde, C. 2002. Pathogen population genetics, evolutionary potential, and durable resistance. Annu. Rev. Phytopathol. 40:349-379.

McDonald, B. A., Mundt, C. C., and Chen, R. S. 1996. The role of selection on the genetic structure of pathogen populations: Evidence from field experiments with Mycosphaerella graminicola on wheat. Euphytica 92:73-80.

Mikaberidze, A., McDonald, B. A., and Bonhoffer, S. 2014. Can high-risk fungicides be used in mixtures without selecting for fungicide resistance? Phytopathology 104:324-331.

Morais, D., Gélisse, S., Laval, V., Sache, I., and Suffert, F. 2016. Inferring the origin of primary inoculum of Zymoseptoria tritici from differential adaptation of resident and immigrant populations to wheat cultivars. Eur. J. Plant Pathol. 145:393-404

Mundt, C. C. 1990. Probability of mutation to multiple virulence and durability of resistance gene pyramids. Phytopathology 80:221-223.

Mundt, C. C. 2002. Use of multiline cultivars and cultivar mixtures for disease management. Annu. Rev. Phytopathol. 40:381-410.

Mundt, C. C., Brophy, L. S., and Schmitt, M. E. 1995. Choosing crop cultivars and mixtures under high versus low disease pressure: A case study with wheat. Crop Prot. 14:509-515.

Mundt, C. C., Cowger, C., and Garrett, K. A. 2002. Relevance of integrated management to resistance durability. Euphytica 124:245-252.

Mundt, C. C., Hoffer, M. E., Ahmed, H. U., Coakley, S. M., DiLeone, J. A., and Cowger, C. 1999. Population genetics and host resistance. Pages 115-130 in: Septoria on Cereals: A Study of Pathosystems. J. A. Lucas, P. Bowyer, and H. M. Anderson, eds. CAB International, Wallingford, UK.

O'Driscoll, A., Kildea, S., Doohan, F., Spink, J., and Mullins, E. 2014. The wheat-Septoria conflict: A new front opening up? Trends Plant Sci. 19:602-610.

Omrane, S., Sghyer, H., Audéon, C., Lanen, C., Duplaix, C., Walker, A. S., and Fillinger, S. 2015. Fungicide efflux and the MgMFS1 transporter contribute to the multidrug resistance phenotype in Zymoseptoria tritici field isolates. Environ. Microbiol. 17:2805-2823.

Paveley, N. D., Sylvester-Bradley, R., Scott, R. K., Craigon, J., and Day, W. 2001. Steps in predicting the relationship of yield on fungicide dose. Phytopathology 91:708-716.

Perelló, A. E., Moreno, M. V., Mónaco, C., Simón, M. R., and Cordo, C. 2009. Biological control of Septoria tritici blotch on wheat by Trichoderma spp. under field conditions in Argentina. BioControl 54:113-122.

Pfender, W. F., and Wootke, S. L. 1988. Microbial communities of Pyrenophorainfested wheat straw as examined by multivariate analysis. Microbiol. Ecol. 15: 95-113.

Ponomarenko, A., Goodwin, S. B., and Kema, G. H. J. 2011. Septoria tritici blotch (STB) of wheat. Plant Health Instructor. Published online. doi: 10.1094/PHI-I-2011-0407-01

Poppe, S., Dorsheimer, L., Happel, P., and Stukenbrock, E. H. 2015. Rapidly evolving genes are key players in host specialization and virulence of the fungal wheat pathogen Zymoseptoria tritici (Mycosphaerella graminicola). PLoS Pathog 11:e1005055.

Quincke, M. C., Murray, T. D., Peterson, C. J., Sackett, K. E., and Mundt, C. C. 2014. Biology and control of cephalosporium stripe of wheat. Plant Pathol. 63:1207-1217.

Rajaram, S., Singh, R. P., and Torres, E. 1988. Current CIMMYT approaches in breeding wheat for rust resistance. Pages 101-108 in: Breeding Strategies for Resistance to the Rusts of Wheat. N. W. Simmonds and S. Rajaram, eds. CIMMYT, Mexico.

Sacristan, S., and Garcia-Arenal, F. 2008. The evolution of virulence and pathogenicity in plant pathogen populations. Mol. Plant Pathol. 9:369-384.

Schafer, J. F., and Roelfs, A. P. 1985. Estimated relation between numbers of urediniospores of Puccinia graminis f. sp. tritici and rates of occurrence of virulence. Phytopathology 75:749-750.

Schuh, W. 1990. Influence of tillage systems on the disease intensity and spatial pattern of Septoria leaf blotch. Phytopathology 80:1337-1340.

Sommerhalder, R. J., McDonald, B. A., Mascher, F., and Zhan, J. 2011. Effect of hosts on competition among clones and evidence of differential selection between pathogenic and saprophytic phases in experimental populations of the wheat pathogen Phaeosphaeria nodorum. BMC Evol. Biol. 11:188.
Stewart, E., and McDonald, B. A. 2014. Measuring quantitative virulence in the wheat pathogen Zymoseptoria tritici using high throughput automated image analysis. Phytopathology 104:985-992.

Stewart, E. L., Croll, D., Lendenmann, M. H., Sanchez-Vallet, A., Hartmann, F. E., Palma-Guerrero, J., Ma, X., and McDonald, B. A. 2016. QTL mapping reveals complex genetic architecture of quantitative virulence in the wheat pathogen Zymoseptoria tritici. bioRxiv 051169.

Stewart, E. L., Hagerty, C. H., Mikaberidze, A., Mundt, C. C., Zhong, Z., and McDonald, B. A. 2016. An improved method for measuring quantitative resistance to the wheat pathogen Zymoseptoria tritici using high throughput automated image analysis. Phytopathology 106:782-788.

Stukenbrock, E. H., Banke, S., Javan-Nikkhah, M., and McDonald, B. A. 2007. Origin and domestication of the fungal wheat pathogen Mycosphaerella graminicola via sympatric speciation. Mol. Biol. Evol. 24:398-411.

Stukenbrock, E. H., Bataillon, T., Dutheil, J. Y., Hansen, T. T., Li, R., Zala, M., McDonald, B. A., Jun, W., and Schierup, M. H. 2011. The making of a new pathogen: Insights from comparative population genomics of the domesticated wheat pathogen Mycosphaerella graminicola and its wild sister species. Genome Res. 21:2157-2166.

Stukenbrock, E. H., and McDonald, B. A. 2008. The origins of plant pathogens in agro-ecosystems. Annu. Rev. Phytopathol. 46:75-100.

Suffert, F., and Sache, I. 2011. Relative importance of different types of inoculum to the establishment of Mycosphaerella graminicola in wheat crops in north-west Europe. Plant Pathol. 60:878-889.

Thrall, P. H., and Burdon, J. J. 2003. Evolution of virulence in a plant host-pathogen metapopulation. Science 299:1735-1737.

Torriani, S. F. F., Brunner, P. C., and McDonald, B. A. 2011. Evolutionary history of the mitochondrial genome in Mycosphaerella populations infecting bread wheat, durum wheat and wild grasses. Mol. Phylogenet. Evol. 58:192-197.

Torriani, S. F. F., Brunner, P. C., McDonald, B. A., and Sierotzki, H. 2009. QoI resistance emerged independently at least four times in European populations of Mycosphaerella graminicola. Pest Manag. Sci. 65:155-162.

Torriani, S. F. F., Melichar, J. P. E., Mills, C., Pain, N., Sierotzki, H., and Courbot, M. 2015. Zymoseptoria tritici: A major threat to wheat production, integrated approaches to control. Fungal Genet. Biol. 79:8-12.

Vanderplank, J. E. 1975. Principles of Plant Infection. Academic Press, New York.

Walters, D. R., and Binghamnn, I. J. 2007. Influence of nutrition on disease development caused by fungal pathogens: Implications for plant disease control. J. Appl. Biol. 151:307-324.

Wolfe, M. S. 1973. Changes and diversity in populations of fungal pathogens. Ann. Appl. Biol. 75:132-136.

Wolfe, M. S. 1985. The current status and prospects of multiline cultivars and variety mixtures for disease resistance. Annu. Rev. Phytopathol. 23:251-273.

Wolfe, M. S., and Barrett, J. A. 1977. Population genetics of powdery mildew epidemics. Ann. N.Y. Acad. Sci. 287:151-163.

Yang, L., Gao, F., Zhan, J., and McDonald, B. A. 2013. Association between virulence and triazole tolerance in the phytopathogenic fungus Mycosphaerella graminicola. PLoS One 8:e59568.

Zhan, J., Kema, G. H. J., Waalwijk, C., and McDonald, B. A. 2002a. Distribution of mating type alleles in the wheat pathogen Mycosphaerella graminicola over spatial scales from lesions to continents. Fungal Genet. Biol. 36:128-136.

Zhan, J., Linde, C. C., Juergens, T., Merz, U., Steinebrunner, F., and McDonald, B. A. 2005. Variation for neutral markers is correlated with variation for quantitative traits in the pathogenic fungus Mycosphaerella graminicola. Mol. Ecol. 14:2683-2693.

Zhan, J., Mundt, C. C., Hoffer, M. E., and McDonald, B. A. 2002b. Local adaptation and effect of host genotype on the evolution of virulence: An experimental test in a plant pathosystem. J. Evol. Biol. 15:634-647.

Zhan, J., Mundt, C. C., and McDonald, B. A. 1998. Measuring immigration and sexual reproduction in field populations of Mycosphaerella graminicola. Phytopathology 88:1330-1337.

Zhan, J., Mundt, C. C., and McDonald, B. A. 2000. Estimating rates of recombination and migration in populations of plant pathogens-A reply. Phytopathology 90:324-326.

Zhan, J., Mundt, C. C., and McDonald, B. A. 2001. Using RFLPs to assess temporal variation and estimate the number of ascospores that initiate epidemics in field populations of Mycosphaerella graminicola. Phytopathology 91:1011-1017.

Zhan, J., Pettway, R. E., and McDonald, B. A. 2003. The global genetic structure of the wheat pathogen Mycosphaerella graminicola is characterized by high nuclear diversity, low mitochondrial diversity, regular recombination, and gene flow. Fungal Genet. Biol. 38:286-297.

Zhan, J., Torriani, S. F. F., and McDonald, B. A. 2007. Significant difference in pathogenicity between MAT1-1 and MAT1-2 isolates in the wheat pathogen Mycosphaerella graminicola. Fungal Genet. Biol. 44:339-346. 